\title{
Sarcopenia and Menopause: The Role of Estradiol
}

\author{
Annalisa Geraci ${ }^{1 *}$, Riccardo Calvani ${ }^{2,3}$, Evelyn Ferri ${ }^{1}$, Emanuele Marzetti ${ }^{2,4}$, \\ Beatrice Arosio ${ }^{1,5}$ and Matteo Cesari ${ }^{5,6}$ \\ ${ }^{1}$ Geriatric Unit, Fondazione IRCCS Ca' Granda Ospedale Maggiore Policlinico, Milan, Italy, ${ }^{2}$ Fondazione Policlinico \\ Universitario "Agostino Gemelli" IRCCS, Rome, Italy, ${ }^{3}$ Aging Research Center, Department of Neurobiology, Care Sciences \\ and Society, Karolinska Institutet and Stockholm University, Stockholm, Sweden, ${ }^{4}$ Institute of Internal Medicine and \\ Geriatrics, Università Cattolica del Sacro Cuore, Rome, Italy, ${ }^{5}$ Department of Clinical Sciences and Community Health, \\ University of Milan, Milan, Italy, ${ }^{6}$ Geriatric Unit, IRCCS Istituti Clinici Scientifici Maugeri, Milan, Italy
}

OPEN ACCESS

Edited by:

James Harper,

Sam Houston State University,

United States

Reviewed by:

Bianca Maria Scicchitano, Catholic University of the Sacred

Heart, Rome, Italy

Peter Tiidus,

Brock University, Canada

*Correspondence: Annalisa Geraci annalisa.geraci@policlinico.mi.it

Specialty section:

This article was submitted to Endocrinology of Aging, a section of the journal Frontiers in Endocrinology

Received: 17 March 2021 Accepted: 05 May 2021

Published: 19 May 2021

Citation:

Geraci A, Calvani R, Ferri E, Marzetti $E$, Arosio $B$ and Cesari $M$ (2021) Sarcopenia and Menopause:

The Role of Estradiol.

Front. Endocrinol. 12:682012. doi: 10.3389/fendo.2021.682012
During aging and menopausal transition in women, a progressive muscle degeneration (i.e. decrease in quality and muscle function) occurs. This muscle dysfunction, caused by decreased proliferation of muscle satellite cells, increased levels of inflammatory markers, and altered levels of sex hormones, exposes women to a raised incidence of sarcopenia. In this regard, hormonal balance and, in particular, estradiol, seems to be essential in skeletal muscle function. The role of the estradiol on satellite cells and the release of inflammatory cytokines in menopausal women are reviewed. In particular, estradiol has a beneficial effect on the skeletal muscle by stimulating satellite cell proliferation. Skeletal muscle can respond to estrogenic hormonal control due to the presence of specific receptors for estradiol at the level of muscle fibers. Additionally, estradiol can limit inflammatory stress damage on skeletal muscle. In this review, we primarily focused on the role of estradiol in sarcopenia and on the possibility of using Estradiol Replacement Therapy, which combined with nutritional and physical activity programs, can counteract this condition representing a valid tool to treat sarcopenia in women.

Keywords: aging, endocrinology, hormones, menopause, muscle

\section{INTRODUCTION}

Sarcopenia is a typical condition of the aging processes that is characterized by decline in muscle mass and quality (1). The sarcopenia onset is determined by hormonal changes, activation of the inflammatory pathway, fat infiltration, apoptosis, and altered mitochondrial function (2). The incidence of some common geriatric syndromes is sex-specific and, in particular, the onset of sarcopenia in women seems to be intimately linked to menopause (3).

One of the most striking phenomena marking women's aging process is menopause, which brings about hormonal changes $(4,5)$ and, in particular, estradiol levels. Estradiol is the most potent estrogen hormone. It regulates the menstrual cycle and is responsible for the development and maintenance of female sexual characteristics. Interestingly, the skeletal muscle possesses specific estradiol receptors at the fiber levels. Therefore estradiol can promote muscle regeneration stimulating the proliferative activity of muscle satellite cells and contributing to muscle health $(6,7)$. 
Muscle satellite cells represent the skeletal muscle stem cells that are responsible for muscle tissue maintenance. Following mechanical stress (e.g., physical exercise) or muscle damage, these cells activate their regenerative function, rebuilding integrity and muscle function (8).

It is to note that the menopausal transition (staged as premenopause, perimenopause, menopause, and post-menopause) (9) is associated not only with a decline in estradiol levels (10), but also with an increased visceral adiposity and decreased bone density, muscle mass, and muscle strength (7) (Figure 1). All these factors significantly contribute to the development of a condition termed "sarcopenic obesity" (11) characterized by a sarcopenic clinical condition and an excessive body weight. Sarcopenic obesity has direct consequences on the health of menopausal and post-menopausal women (12).

Interestingly, estradiol is also involved in the modulation of the local and systemic inflammatory responses thus affecting sarcopenia $(13,14)$.

In this review, we will discuss the role of serum estradiol concentrations on the incidence of sarcopenia in menopausal women. In particular, we will provide a brief overview of the estradiol effects on muscle satellite cells and the release of inflammatory cytokines, hypothesizing a possible target for sarcopenia interventions in women.

\section{ESTRADIOL DEFICIT AND INFLAMMATION}

Evidence suggests that menopause is closely associated with an increased release of pro-inflammatory cytokines, such as interleukin (IL)-6, IL-1, and tumor necrosis factor- $\alpha$ (TNF- $\alpha$ ) (15).

Notably, some studies have suggested how adipocytes, through the release of IL- 6 and TNF- $\alpha$, can promote the accumulation of fat mass and compromise muscle function (16-18), thus causing sarcopenia (19-21).

Although there is a clear correlation between increased peripheral IL-6 and TNF- $\alpha$ levels with sarcopenia, the causes and mechanisms remain partially unclear.

Nonetheless, studies have shown the capability of $17 \beta$ estradiol to specifically inhibit the inflammation-mediated release of some pro-inflammatory cytokines, like TNF- $\alpha$ (22), which can degrade muscle proteins and reduce the ability of the adult muscle to respond to damage (23).

An exciting aspect resides in the ability of estrogen treatment to attenuate fat gain and decreased lean mass, modulating the inflammation in the skeletal muscle and thus reducing the risk of "sarcopenic obesity" $(12,24)$. In this regard, there are convincing lines of evidence on the ability of estrogens to act and influence adipose tissue directly through the estrogen receptor- $\alpha$ (16).

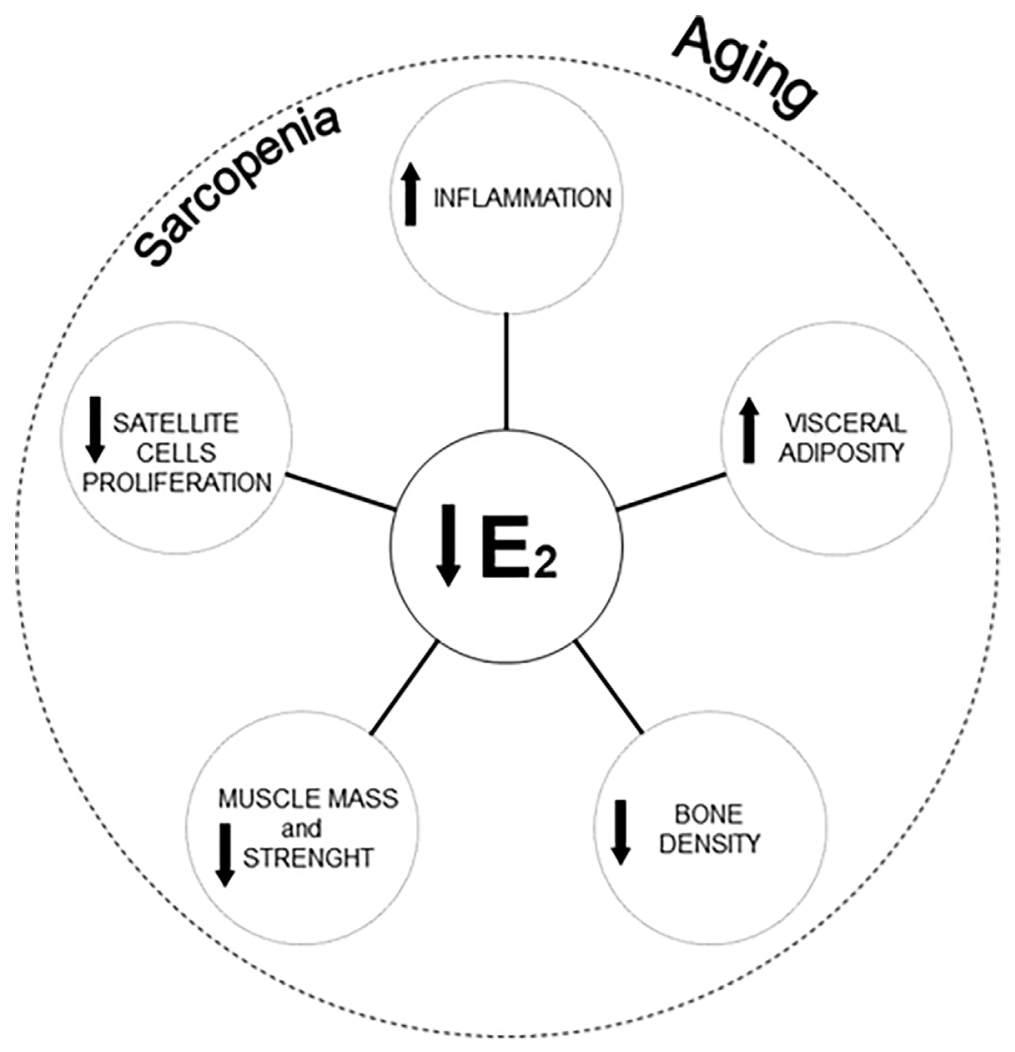

FIGURE 1 | Reduction of estradiol concentrations, morphological changes, and cellular modifications affecting sarcopenia in women aging. E2, Estradiol. 
Under these premises, the fact that estrogen can inhibit the inflammatory response could be of extreme interest to prevent further damage (25).

\section{ROLE OF ESTRADIOL IN SKELETAL MUSCLE STEM CELL PHYSIOLOGY}

Muscle fibers house a population of stem cells (satellite cells), ensuring plasticity and regeneration (26). These cells are abundant during the early phases of development, contributing to muscle growth and then decrease over time (27). Their content varies depending on fiber types. Type I oxidative fibers have a higher content of satellite cells than type II fibers because they benefit from more significant blood and capillary contribution (26).

In steady-state conditions, satellite cells are in a quiescent state $(28,29)$. Following muscle injury or anabolic stimulation, they are activated and enter the myogenic program to support the repair of muscle damage through fiber repair or growth $(30,31)$

The age-related chronic inflammatory state impacts the proliferation and the replenishment of satellite cells (26). In this regard, the role played by estradiol becomes of considerable interest. Estradiol stimulates the activation and, consequently, the proliferation of satellite cells through specific estrogen receptors (ER; e.g., ER- $\alpha$ and ER- $\beta$ ) (32) (Figure 1), promoting muscle repair $(5,7,13,33)$.

Nevertheless, the ability of estradiol to make the skeletal muscle generating force (13) seems to exclusively depend on the binding of this hormone with the receptor- $\alpha(13,34)$.

\section{FUTURE PERSPECTIVES}

There is convincing evidence that estrogens and, especially, estradiol play a key role in the preservation of muscle health in old age (35).

In this regard, several research studies on interventions aimed at hormone replacement have been conducted. In some cases, hormone supplementation (or HRT, Hormone Replacement Therapy) with estradiol has generated enormous interest for its potentially beneficial effects $(36,37)$. Specifically, menopauserelated obesity and loss of lean and skeletal muscle mass have been shown to reverse following estradiol hormone therapy (38).

In addition, estrogen replacement has shown different effects by performing it in a specific phase of menopause. Specifically,

\section{REFERENCES}

1. Landi F, Calvani R, Cesari M, Tosato M, Martone AM, Ortolani E, et al. Sarcopenia: An Overview on Current Definitions, Diagnosis and Treatment. Curr Protein Pept Sci (2018) 19(7):633-8. doi: 10.2174/1389203 718666170607113459

2. Walston JD. Sarcopenia in Older Adults. Curr Opin Rheumatol (2012) 24 (6):623-7. doi: 10.1097/BOR.0b013e328358d59b the use of HRT in the "initial post-menopause" compared to a "delayed post-menopause" phase resulted in a significant increase in the number of muscle satellite cells (39) as well as in an improvement of mobility and muscle strength (40).

Conversely, it should be noted that some studies have considered Estradiol Replacement Therapy (ERT) an ineffective method against muscle loss (35). Others have found an association of hormone therapy with an increased risk of breast cancer (41) and/or cardiovascular disease (42).

Nonetheless, the effects of hormone therapy still remain, however, controversial. For all these reasons, lifestyle interventions (in particular physical activity and nutritional interventions) currently remain the cornerstones for maintaining muscle health into advanced age (43). Large research programs [e.g., the Sarcopenia and Physical fRailty IN older people: multi-componenT Treatment strategies (SPRINTT) project] $(44,45)$ have been conducted to define the critical steps for facilitating the development of pharmacological interventions against sarcopenia. Researchers are defining the regulatory framework for offering (pharmacological) opportunities to treat or prevent sarcopenia and its adverse outcomes (46).

Women not adequately responding to lifestyle intervention, for example, could combine a physical-rehabilitation and nutritional program with ERT to improve their health condition for preserving muscle mass and function into late life. Of course, studies supporting this hypothesis are needed.

\section{DISCUSSION}

Although the mechanisms related to muscle loss in menopausal and post-menopausal women require further studies, the idea of using ERT in addition to nutritional and physical programs for tackling sarcopenia might be interesting to explore. The fact that inflammation is positively influenced by estradiol may provide a solid biological background to the hypothesis. Novel therapeutic perspectives based on the estradiol effects might become fundamental in the future to prevent/delay the development of sarcopenia in aging women.

\section{AUTHOR CONTRIBUTIONS}

$\mathrm{AG}, \mathrm{EM}$, and $\mathrm{MC}$ drafted the manuscript. RC, EF, and BA provided critical revision. All authors contributed to the article and approved the submitted version.

3. Yang L, Smith L, Hamer M. Gender-Specific Risk Factors for Incident Sarcopenia: 8-Year Follow-Up of the English Longitudinal Study of Ageing. J Epidemiol Community Health (2019) 73(1):86-8. doi: 10.1136/jech-2018211258

4. Carr MC. The Emergence of the Metabolic Syndrome With Menopause. J Clin Endocrinol Metab (2003) 88(6):2404-11. doi: 10.1210/jc.2003-030242

5. Messier V, Rabasa-Lhoret R, Barbat-Artigas S, Elisha B, Karelis AD, Aubertin-Leheudre M. Menopause and Sarcopenia: A Potential Role for 
Sex Hormones. Maturitas (2011) 68(4):331-6. doi: 10.1016/j.maturitas. 2011.01.014

6. Cruz-Jentoft AJ, Baeyens JP, Bauer JM, Boirie Y, Cederholm T, Landi F, et al. Sarcopenia: European Consensus on Definition and Diagnosis: Report of the European Working Group on Sarcopenia in Older People. Age Ageing (2010) 39(4):412-23. doi: 10.1093/ageing/afq034

7. La Colla A, Pronsato L, Milanesi L, Vasconsuelo A. 17beta-Estradiol and Testosterone in Sarcopenia: Role of Satellite Cells. Ageing Res Rev (2015) 24 (Pt B):166-77. doi: 10.1016/j.arr.2015.07.011

8. Forcina L, Miano C, Pelosi L, Musaro A. An Overview About the Biology of Skeletal Muscle Satellite Cells. Curr Genomics (2019) 20(1):24-37. doi: 10.2174/1389202920666190116094736

9. Shepherd R, Cheung AS, Pang K, Saffery R, Novakovic B. Sexual Dimorphism in Innate Immunity: The Role of Sex Hormones and Epigenetics. Front Immunol (2020) 11:604000. doi: 10.3389/fimmu.2020.604000

10. Baber RJ, Panay N, Fenton A. 2016 IMS Recommendations on Women's Midlife Health and Menopause Hormone Therapy. Climacteric (2016) 19 (2):109-50. doi: 10.3109/13697137.2015.1129166

11. Ezzat-Zadeh Z, Kim JS, Chase PB, Arjmandi BH. The Cooccurrence of Obesity, Osteoporosis, and Sarcopenia in the Ovariectomized Rat: A Study for Modeling Osteosarcopenic Obesity in Rodents. J Aging Res (2017) 2017:1454103. doi: 10.1155/2017/1454103

12. Lee H, Kim YI, Nirmala FS, Kim JS, Seo HD, Ha TY, et al. MiR-141-3p Promotes Mitochondrial Dysfunction in Ovariectomy-Induced Sarcopenia Via Targeting Fkbp5 and Fibin. Aging (Albany NY) (2021) 13:4881-94. doi: 10.18632/aging.202617

13. Collins BC, Arpke RW, Larson AA, Baumann CW, Xie N, Cabelka CA, et al. Estrogen Regulates the Satellite Cell Compartment in Females. Cell Rep (2019) 28(2):368-81 e6. doi: 10.1016/j.celrep.2019.06.025

14. Juppi HK, Sipila S, Cronin NJ, Karvinen S, Karppinen JE, Tammelin TH, et al. Role of Menopausal Transition and Physical Activity in Loss of Lean and Muscle Mass: A Follow-Up Study in Middle-Aged Finnish Women. J Clin Med (2020) 9(5):1588. doi: 10.3390/jcm9051588

15. Cioffi M, Esposito K, Vietri MT, Gazzerro P, D’Auria A, Ardovino I, et al. Cytokine Pattern in Postmenopause. Maturitas (2002) 41(3):187-92. doi: 10.1016/s0378-5122(01)00286-9

16. Arthur ST, Cooley ID. The Effect of Physiological Stimuli on Sarcopenia; Impact of Notch and Wnt Signaling on Impaired Aged Skeletal Muscle Repair. Int J Biol Sci (2012) 8(5):731-60. doi: 10.7150/ijbs.4262

17. Buford TW, Anton SD, Judge AR, Marzetti E, Wohlgemuth SE, Carter CS, et al. Models of Accelerated Sarcopenia: Critical Pieces for Solving the Puzzle of Age-Related Muscle Atrophy. Ageing Res Rev (2010) 9(4):369-83. doi: 10.1016/j.arr.2010.04.004

18. Roth SM, Metter EJ, Ling S, Ferrucci L. Inflammatory Factors in Age-Related Muscle Wasting. Curr Opin Rheumatol (2006) 18(6):625-30. doi: 10.1097/ 01.bor.0000245722.10136.6d

19. Dobs AS, Nguyen T, Pace C, Roberts CP. Differential Effects of Oral Estrogen Versus Oral Estrogen-Androgen Replacement Therapy on Body Composition in Postmenopausal Women. J Clin Endocrinol Metab (2002) 87(4):1509-16. doi: $10.1210 /$ jcem. 87.4 .8362

20. Iannuzzi-Sucich M, Prestwood KM, Kenny AM. Prevalence of Sarcopenia and Predictors of Skeletal Muscle Mass in Healthy, Older Men and Women. J] Gerontol A Biol Sci Med Sci (2002) 57(12):M772-7. doi: 10.1093/gerona/ 57.12.m772

21. Leveille SG. Musculoskeletal Aging. Curr Opin Rheumatol (2004) 16(2):114-8. doi: 10.1097/00002281-200403000-00007

22. Lambert KC, Curran EM, Judy BM, Lubahn DB, Estes DM. Estrogen Receptor-Alpha Deficiency Promotes Increased TNF-alpha Secretion and Bacterial Killing by Murine Macrophages in Response to Microbial Stimuli In Vitro. J Leukoc Biol (2004) 75(6):1166-72. doi: 10.1189/jlb.1103589

23. Li YP, Reid MB. NF-KappaB Mediates the Protein Loss Induced by TNFalpha in Differentiated Skeletal Muscle Myotubes. Am J Physiol Regul Integr Comp Physiol (2000) 279(4):R1165-70. doi: 10.1152/ajpregu.2000. 279.4.R1165

24. Gambacciani M, Ciaponi M, Cappagli B, De Simone L, Orlandi R, Genazzani AR. Prospective Evaluation of Body Weight and Body Fat Distribution in Early Postmenopausal Women With and Without Hormonal Replacement Therapy. Maturitas (2001) 39(2):125-32. doi: 10.1016/s0378-5122(01)00194-3
25. Le G, Novotny SA, Mader TL, Greising SM, Chan SSK, Kyba M, et al. A Moderate Oestradiol Level Enhances Neutrophil Number and Activity in Muscle After Traumatic Injury But Strength Recovery is Accelerated. J Physiol (2018) 596(19):4665-80. doi: 10.1113/JP276432

26. Hawke TJ, Garry DJ. Myogenic Satellite Cells: Physiology to Molecular Biology. J Appl Physiol (1985) (2001) 91(2):534-51. doi: 10.1152/jappl.2001. 91.2.534

27. Kadi F, Charifi N, Denis C, Lexell J. Satellite Cells and Myonuclei in Young and Elderly Women and Men. Muscle Nerve (2004) 29(1):120-7. doi: 10.1002/ mus. 10510

28. Keefe AC, Lawson JA, Flygare SD, Fox ZD, Colasanto MP, Mathew SJ, et al. Muscle Stem Cells Contribute to Myofibres in Sedentary Adult Mice. Nat Commun (2015) 6:7087. doi: 10.1038/ncomms8087

29. Kuang S, Kuroda K, Le Grand F, Rudnicki MA. Asymmetric Self-Renewal and Commitment of Satellite Stem Cells in Muscle. Cell (2007) 129(5):999-1010. doi: 10.1016/j.cell.2007.03.044

30. Hindi SM, Kumar A. TRAF6 Regulates Satellite Stem Cell Self-Renewal and Function During Regenerative Myogenesis. J Clin Invest (2016) 126(1):15168. doi: 10.1172/JCI81655

31. Dumont NA, Bentzinger CF, Sincennes MC, Rudnicki MA. Satellite Cells and Skeletal Muscle Regeneration. Compr Physiol (2015) 5(3):1027-59. doi: $10.1002 /$ cphy.c140068

32. Velders M, Schleipen B, Fritzemeier KH, Zierau O, Diel P. Selective Estrogen Receptor-Beta Activation Stimulates Skeletal Muscle Growth and Regeneration. FASEB J (2012) 26(5):1909-20. doi: 10.1096/fj.11-194779

33. Morley JE, Malmstrom TK. Frailty, Sarcopenia, and Hormones. Endocrinol Metab Clin North Am (2013) 42(2):391-405. doi: 10.1016/j.ecl.2013.02.006

34. Collins BC, Mader TL, Cabelka CA, Inigo MR, Spangenburg EE, Lowe DA. Deletion of Estrogen Receptor Alpha in Skeletal Muscle Results in Impaired Contractility in Female Mice. J Appl Physiol (1985) (2018) 124(4):980-92. doi: 10.1152/japplphysiol.00864.2017

35. Kenny AM, Dawson L, Kleppinger A, Iannuzzi-Sucich M, Judge JO. Prevalence of Sarcopenia and Predictors of Skeletal Muscle Mass in Nonobese Women Who are Long-Term Users of Estrogen-Replacement Therapy. J Gerontol A Biol Sci Med Sci (2003) 58(5):M436-40. doi: 10.1093/gerona/58.5.m436

36. Kase NG, Gretz Friedman E, Brodman M, Kang C, Gallagher EJ, LeRoith D. The Midlife Transition and the Risk of Cardiovascular Disease and Cancer Part I: Magnitude and Mechanisms. Am J Obstet Gynecol (2020) 223(6):82033. doi: 10.1016/j.ajog.2020.05.051

37. Maki PM, Girard LM, Manson JE. Menopausal Hormone Therapy and Cognition. Bmj (2019) 364:1877. doi: 10.1136/bmj.1877

38. Sorensen MB, Rosenfalck AM, Hojgaard L, Ottesen B. Obesity and Sarcopenia After Menopause are Reversed by Sex Hormone Replacement Therapy. Obes Res (2001) 9(10):622-6. doi: 10.1038/oby.2001.81

39. Mangan G, Iqbal S, Hubbard A, Hamilton V, Bombardier E, Tiidus PM. Delay in Post-Ovariectomy Estrogen Replacement Negates Estrogen-Induced Augmentation of Post-Exercise Muscle Satellite Cell Proliferation. Can J Physiol Pharmacol (2015) 93(11):945-51. doi: 10.1139/cjpp-2015-0106

40. Ronkainen PH, Kovanen V, Alen M, Pollanen E, Palonen EM, AnkarbergLindgren C, et al. Postmenopausal Hormone Replacement Therapy Modifies Skeletal Muscle Composition and Function: A Study With Monozygotic Twin Pairs. J Appl Physiol (1985) (2009) 107(1):25-33. doi: 10.1152/japplphysiol. 91518.2008

41. Kim S, Ko Y, Lee HJ, Lim JE. Menopausal Hormone Therapy and the Risk of Breast Cancer by Histological Type and Race: A Meta-Analysis of Randomized Controlled Trials and Cohort Studies. Breast Cancer Res Treat (2018) 170(3):667-75. doi: 10.1007/s10549-018-4782-2

42. Basaria S, Coviello AD, Travison TG, Storer TW, Farwell WR, Jette AM, et al. Adverse Events Associated With Testosterone Administration. N Engl J Med (2010) 363(2):109-22. doi: 10.1056/NEJMoa1000485

43. Azzolino D, Damanti S, Bertagnoli L, Lucchi T, Cesari M. Sarcopenia and Swallowing Disorders in Older People. Aging Clin Exp Res (2019) 31(6):799805. doi: 10.1007/s40520-019-01128-3

44. Marzetti E, Calvani R, Tosato M, Cesari M, Di Bari M, Cherubini A, et al. Sarcopenia: An Overview. Aging Clin Exp Res (2017) 29(1):11-7. doi: 10.1007/ s40520-016-0704-5

45. Cesari M, Landi F, Calvani R, Cherubini A, Di Bari M, Kortebein P, et al. Rationale for a Preliminary Operational Definition of Physical Frailty and 
Sarcopenia in the SPRINTT Trial. Aging Clin Exp Res (2017) 29(1):81-8. doi: 10.1007/s40520-016-0716-1

46. Del Signore S, Roubenoff R. Physical Frailty and Sarcopenia (PF\&S): A Point of View From the Industry. Aging Clin Exp Res (2017) 29(1):69-74. doi: 10.1007/s40520-016-0710-7

Conflict of Interest: The authors declare that the research was conducted in the absence of any commercial or financial relationships that could be construed as a potential conflict of interest.
The reviewer BS declared a shared affiliation with some of the authors, RC and $\mathrm{EM}$, to the handling editor at time of review.

Copyright $\odot 2021$ Geraci, Calvani, Ferri, Marzetti, Arosio and Cesari. This is an openaccess article distributed under the terms of the Creative Commons Attribution License (CC BY). The use, distribution or reproduction in other forums is permitted, provided the original author(s) and the copyright owner(s) are credited and that the original publication in this journal is cited, in accordance with accepted academic practice. No use, distribution or reproduction is permitted which does not comply with these terms. 